\title{
Pro-drop in Standard Arabic
}

\author{
Bashir M. Alnajadat ${ }^{1}$ \\ ${ }^{1}$ Department of English, Faculty of Preparatory Year and Supporting Studies, University of Dammam, KSA \\ Correspondence: Bashir M. Alnajadat, Department of English, Faculty of Preparatory Year and Supporting \\ Studies, University of Dammam, P. O. Box 1982, KSA. E-mail: bashir.najadat@yahoo.com or \\ bmnajadat@uod.edu.sa
}

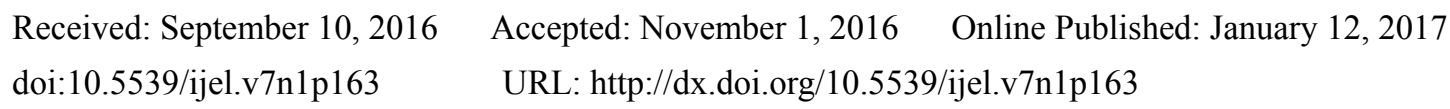

\begin{abstract}
The correlation between Pro-drop and the nature of verbal morphology is a universal principle. This syntactic phenomenon has been parameterized on the basis of verb inflection. Rich verbal inflection has been advocated to allow pro-drop subject. On contrast, if a language structure maintains a low level of verbal morphology, pro will not be dropped. This paper comes to show that Standard Arabic (SA) is a partial pro-drop language. It has null subject even with rich verbal inflection structure. Nonetheless, the paper shows that in some forms of imperative sentence that have poor verbal inflection, but the subject is optional. On the other side, and on the basis of minimalism, pro is asserted to have features that must be checked in the course of derivation. These features are case and agreement that can be valued at Specifier-head configuration to pro. The process of checking optimally tries to draw evidence for the minimum level of morpho-syntactic features that pro in SA carries.
\end{abstract}

Keywords: pro-drop, Standard Arabic, parameter, inflection morphology, agreement

\section{Introduction}

The term pro-drop has been already formed by Chomsky (1981) in his masterwork of (Lectures on Government and Binding). According to Universal Grammar (UG), and in the Principles and Parameters (PP) framework, the concept of pro-drop is justified by cross-linguistic evidences. This syntactic property is based on the idea that rich verbal morphology allows subject pronoun deletion. On contrast, non-rich verb morphology is assumed to disallow this syntactic feature. This phenomenon is classified as parameterized cross-languages due to structure-dependent principle. Hence some languages such as Italian is said to be (+ pro-drop) language as seen in sentence (1), whereas English is (-pro-drop) language as in sentence (2). Obviously, a language according to this scenario can be classified on the basis of rich or non-rich verbal morphology into [+/- language]. Standard Arabic (SA), as a Semitic language, with high level of rich morphology, allows subject drop in initial position as shown in (3). In fact, the conjugation system of the verb as in (rakib-a) of sentence (3) can compensate the absence of the subject. The verb conjugation is rich too and has the property of introflection in which the root can be modified to fulfill a new morphosyntactic requirement in the structure.

1).......mangio la riso

$\varnothing$ eat the rice

"(I) eat the rice"

2). *... usually eats there.

3). ...... rakib-a ?ssayara-t-a

(He) ride. pst the car

"he rode the car"

The verb as seen in (3) encodes a sufficient morpho-syntactic indication to the agent of the action. Therefore, the presence of the pronominal subject in initial position will be redundant. This process of subject property seems as a structural variation that allows speaker/writer to express the content with two options: null or overt subject whose meaning can be preserved. Thus such process is a reflection to phonetic conditioning and simple repetition of preceding structure as Labov (1994) stated. However, the omission of the subject in SA is grammatical, especially when the subject has a preceding known reference, see Rizzi (1982 \& 1986). This state 
to some extent in traditional grammar has distinguished languages that have such morpho-syntactic property as Null Subject Languages (NSLs). Nonetheless, the current studies came to draw evidences that pro-drop is instead a cross-language varied.

\section{Pro-drop and SA Morphology}

According to syntactic studies, pro-drop phenomenon is as a result of verbal morphology richness. This property plays a central role of pro-drop in SA. Inflection correspondence seems flexible in verbal richness which appears in different forms. In fact, it is irregular. To clarify, Arabic has a plenty of both prefixes and suffixes that perform different functions and morpho-syntactic indications. Moreover, SA has a nonconcatenative verbal system that permits infixation as stated by MecCrathy (1981). This property could be proposed to enrich both inflectional and derivational system of SA. In this topic, and in terms of tense, SA has two sets of verbal tense: perfect and imperfect. The perfect refers to past, whereas the imperfect indicates present or future. In fact, prefix and suffix encode other sorts of declension namely, number, gender, and case as seen in table 1:

Table 1. The verbal paradigm of the verb (yashrab-drink) in SA

\begin{tabular}{lllll}
\hline \multirow{2}{*}{ Number } & Subject & Perfect & Imperfect & \\
\cline { 2 - 5 } & Person & Past & Present & future \\
\hline \multirow{2}{*}{ ingular } & Ana-1.sg.msc/fem & sharibt-u & ?shrab-u & Sa-?shrab-u \\
& Anta.1.sg.msc & sharibt-a & Tashrab-u & Sa-tashrab-u \\
& Anti-1.sg.fem & sharib-ti & Tashrab-i & Sa-tashrab-i \\
& Huwa.1.sg.msc & sharib-a & Yashrab-u & Sa-yashrab-u \\
& Hiya.1.sg.fem & shariba-t & Ta-shrab-u & Sa-tashrab-u \\
\hline Dual & Antuma.2.dul.msc & sharib-tu-m & Tashrb-an & Sa-tashrb-an \\
& Antuma.2.dul.fem & sharib-tu-n & Tashrb-na & Sa-tashrb-na \\
\hline \multirow{2}{*}{ Plural } & Nahnu.1.plu.msc/fem & sharib-na & Nashrab-u & Sa-nashrab-u \\
& Antum.3.plu.msc & sharib-t-um & Tashrab-oun & Sa-tashrab-oun \\
& Antun-a.3.plu,fem & sharib-t-una & Tashrab-na & Sa-tashrab-na \\
& Hum. 3.plu.msc & sharib-u & Yashrab-oun & Sa-yashrab-oun \\
& Huna.3.plu,fem & sharib-na & Yashrab-na & Sa-yashrab-na \\
\hline
\end{tabular}

The table shows how prefix and suffix joined to the verb (yashrab). The infixes serve to indicate tense, gender, person, number and case. The last three features can be assumed to be constrained with tense, e.g., in (Anta.2.sg.msc), in which the suffix appears different with regard to tense, it is (-a) in perfect tense, but (-u) in imperfect. Further, such suffix comes to retain $\phi$-features, e.g., the suffix (-u) can be advocated by scholars to encode [person, number, gender]. It also can function as nominative case marker. The problem arises here is that the boundary between suffix-type and feature distinction is unclear. To exemplify, the suffix (-na) indicates to both masculine and feminine feature, and the distinction can be through context or other category insertion. In this way, and regardless inconsistent form of affixation in SA, this property provides an interpretation to pro as a referential subject that has features such as [person, number, gender, case].

\section{Trouble with Imperative and Equational Forms}

Equational sentence usually lacks to tense in SA. This issue represents a central problem to inflection that requires fully inflected forms for pro to drop. On the other side, in imperative form of SA, the subject is usually dropped. It can be figured out as in (?nta- you). Obviously, such form comes to provide with persuasive evidence that refutes the general theory of Pro-drop as a reflection to rich verbal inflection. In (4.a) the verb (sa?ed- help) that indicates imperative mood is equal to the counterpart verb of English. Such a verb is originally derived from jussive verb, which according to Wright (1967) has no tense inflection as seen in (4.a):
4). a. Sa?ed
$\varnothing \quad$ ?nnas-a
Help.impr.2.sg.msc $\quad \varnothing \quad$ the people
"help the people"

b. Sa?ed (?nata) ?nnas-a

Help.impr.2.sg.msc (you) 2.sg.msc the people

"you help the people"

The previous examples of imperative variable form are evidence against the assumption that rich verbal 
inflection results to pro-drop. In fact, this might be positive property in finite clause of SA as in sentence (3), but in imperative clause, the subject is usually covert. This state of pro-drop is, however, not as a reflex to rich morphology of the verb. The property becomes complicated when we draw a further form of imperative in which pro-drop is optional as the previous sentence of (4.b). This process of implicit and explicit subject has been explained in traditional grammar of Arabic as proposed by Iben Aqeil (11th century). However, on the basis of inflection, we can say that verbal morphology is not restricted to tense, but can involve other inflectional elements such as agreement (AGR). Thus, as Chomsky (1981) was impressed by Taraldsen (1978) proposal that AGR can results into pro-drop, we can admit that this inflectional feature seems positive when full agreement between the verb (sa?ed) and the dropped subject as in (4.a) represented by (Ø), which is the same as in (4.b) of (?nta- you.2.sg.msc). This state of affairs could permit one to claim that INFL is a double standard property that once it forces dropping subject and in another validates subject overtness.

\section{AGR Variance with Pro-drop}

Imperative structure in SA has different forms on the basis of subject-verb agreement. In the previous section, we displayed how [2.sg.msc] pro match with the same set of $\phi$-features of the verb (sa?ed) results to pro-drop. On contrast, dual and plural forms of the imperative verb do not match with pro to be dropped as seen in (5.a \& b):

$\begin{array}{lll}\text { 5). a. sa?ed-aa } & \varnothing & \text { ?nnas-a } \\ \text { Help.impr.2.dul.msc } & \text { ec } & \text { the people } \\ \text { "you both help the people" } & & \\ \begin{array}{l}\text { b. sa?ed-u } \\ \text { Help.impr.3.plu.msc ec }\end{array} & \text { ?nnas-a } \\ \text { "you help the people" } & & \end{array}$

In this scenario, we can formulate a mathematical formula for tense and agreement inflection that determines tentatively the relation between inflection and pro-drop in SA. The following figure 1 shows how structure-independence principle of imperative form produces inconsistency to pro-drop general theory.

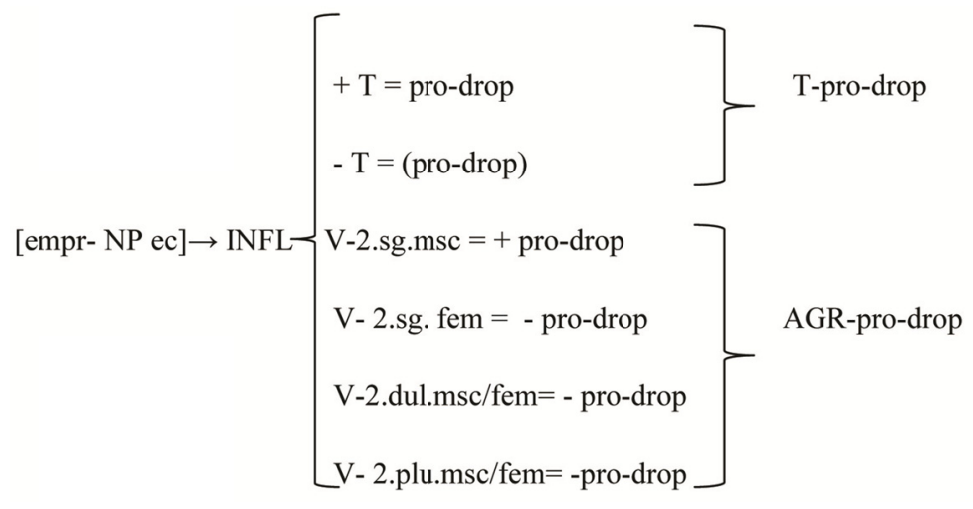

Figure 1. Shows the status of imperative form tense and agreement inflection

In the view of this chart, one can try to formulate a morphological uniform of inflectional paradigm to account for the status of inflectional forms as Jaeggli \& Safir (1989, p. 29) suggested. Number and gender features according to the figure have a distinctive morphological paradigm that somewhat disallows pro-drop. However, apart from syntactic account, we can propose the idea of Topic Chaining (See Jaeggli \& Safir, 1989) in which such case of poor morphology, subject recovering can be in the light of discourse oriented context wherein topic deleted can be identified in proceedings. In this proposal we can rescue structures with poor (AGR, TP) but has pro-drop. Thus the topic/subject of sentence $(5 . a, b)$ can be touched from the context or proceeding sentences.

\section{Pro-drop in Embedded Clause}

In the previous section, I presented pro-drop operation in finite and imperative clause, which both maintain different result to null subject as a reflex to INFL. Now, I will show how pro-drop occurs in embedded clause which involves the operation that associates with INFL. The embedded clause can take subjunctive mood that 
allows pro-drop. The matrix clause of such type contains verbs such as (yatmana-wish), expresses inclination, imposes pro to be null as shown in (6).
6). taman-a
?1-mu?lim-u
[?nn yaktub-a
$\varnothing$
?nnass-a]

Wish.3.sg.msc.Pst the teacher. Nom [that (he) write.3.sg.msc

ec.3.sg.msc the text.Acc]

"the teacher wished that (he) write the text"

The covert subject in (6) can be illustrated or encoded by a multi affixation that can involve prefix(y) and the final suffix (-a) of the verb (yaktub-a). This part stands for the estimated subject of (hwa-3.sg.msc-he). The claim is proved by the test of replacement. Thus if we replace (y) by (n), then we have subject marker of (1.plu.msc/fem). However, the role of INFL is variable here. It is negative for [T] that has to appear in present form for the verb (yaktub). Otherwise, the sentence will be rendered ungrammatical. On the other side, AGR seems positive. Both the verb (yaktub) and the null subject (Ø) are matched in [number, person, and gender]. In such structure properties, one can propose that rich/match of AGR morphology between the verb and the pro contributes to pro-drop operation in the subjunctive embedded clause.

The pro-drop in SA extends to other embedded clauses. It can occur in wh-embedded clause. In this clause, a pro appears in final position. The null subject can be figured out as (I), which bears AGR feature with post-categories usually in the form of lexical verb as shown in (7).

$\begin{array}{llll}\text { 7). laa ?a?rif-u } & \text { maTHa } & \text { ?-goul-u } & \varnothing \\ \text { No 1.sg.msc know } & \text { what } & \text { prs 1.sg.msc.say. } & \text { 1.sg.msc } \\ \text { "I do not know what to say" } & & & \end{array}$

The AGR seems a plausible motive for pro-drop in such structure. Obviously, the marker (?-) in the verb (?-goul-u) agrees in [person, number, gender] with the dropped subject (Ø). The remarkable issue in this clause is that [T] manifests full inflection with (Ø) in which the verb (yagoul) can be inflected for tense with a rational little change in prefix and suffix that seems to serve null subject correspondence for both AGR and T as shown in table 2 for present tense verb-subject conjugation:

Table 2. Present tense verb conjugation system in SA

\begin{tabular}{|c|c|c|c|c|c|}
\hline \multirow[t]{2}{*}{ Tense } & \multicolumn{3}{|c|}{ Verb Conjugation } & \multicolumn{2}{|l|}{ AGR } \\
\hline & Prefix & Root & Suffix & Prefix Interpretation & Suffix Interpretation \\
\hline \multirow[t]{11}{*}{ Present } & $?-$ & goul- & $\mathrm{u}$ & (?) $1 . \mathrm{sg} . \mathrm{msc} / \mathrm{fem}$ & (-u)1.sg.msc/fem \\
\hline & $\mathrm{Na}-$ & goul- & $\mathrm{u}$ & (Na).1.plu.msc/fem & (-u) 1.plu.msc/fem \\
\hline & Ta- & goul- & $\mathrm{u}$ & (Ta). 2.sg.msc & $(-\mathrm{u}) 2 . \mathrm{sg} \cdot \mathrm{msc}$ \\
\hline & Ta- & goul- & ien & (Ta). 2.sg.fem & (ien).2.sg.fem \\
\hline & Ta- & goul- & oun & (Ta-).2.plu.msc & (-oun)2.plu.msc \\
\hline & Ta- & goul- & na & (Ta).2.plu.fem & (-na).2.plu.fem \\
\hline & Ta- & goul- & an & (Ta-).2.dul. $\mathrm{msc} / \mathrm{fem}$ & (-an)2.dul.msc/fem \\
\hline & Ya- & goul- & $\mathrm{u}$ & (ya).3.sg.msc & $(-u) 3 . s g \cdot m s c$ \\
\hline & Ta- & goul- & $\mathrm{u}$ & (Ta).3.sg.fem & \\
\hline & Ya- & goul-u & (n) & (ya-).3.plu.msc & \\
\hline & Ya- & goul- & na & (ya-).3.plu.fem & (-na)3.plu.fem \\
\hline
\end{tabular}

In the table we see a complex system of verb inflection. There seems vague issue in the prefixes (Ta- and Na) that appear to have the same [T] marking. The fact, is that, the present tense can be indicated or get marked by any of these prefixes of (n, a, t, y). Prefix-suffix match depends mainly on context-interpretation. In the previous table, a prefix such as (ta-) and a suffix like (-u) can be interpreted differently on the basis of structure properties. This set of initials functionally occurs to serve both $[\mathrm{T}]$ and [AGR] as well. Thus, the seemingly symmetric complex INFL of $[\mathrm{T}]$ and [AGR] instantiate subject desirable implicit indication (Note 1) which is a reflex to finite verb inflection.

Null subject in SA can appear in adverbial embedded clause as well. The pro has implicit from reflected in past tense of the embedded verb. AGR correspondence appears clearly between the verb (?nhayt-u) as seen in sentence (8) and the pro (Ø). The INFL seems liable to [T] and changes accordingly. 


\begin{tabular}{|c|c|c|c|c|c|}
\hline 8). Gadar-a & Ali-un & ؟indama & ?nhayt-u & $\varnothing$ & ?1-hadieth-a \\
\hline Leave.pst & Ali.Nom & when & finish.pst1.sg.msc & 1.sg.msc & the speech \\
\hline
\end{tabular}

The various phi-features of the system of prefix and suffix in SA give rise here to characterize the nature of pro in terms of which phi-feature it maintains. So, this again, provides with further evidence on the direct relationship between pro and the system of affixation. For instance, a prefix such as (Na or $\mathrm{Ta}$ ) can tell a reader about the token phi- feature of pro, and the same approximately applies to suffix such as ( $u$ and an) that with context can provide which feature of AGR that a pro carries. The overall AGR in both verbal and nominal aspect of pro can be assumed as essential part of the entire INFL that can determine particular features such as case of pro which will be discussed in next section.

\section{Pro Case Assignment}

In (1982) Chomsky explained the relation between pro- parameter and case assignment. That is, for him, agreement is proposed as a motive for pro case assignment of these languages that permit pro-drop such as Italian. Then Chomsky \& Lasnik (1993) modified their earlier view about PRO. They admitted it to be assigned null case, lexically licensed by non-finite $I^{0}$. This proposal alternates Chomsky (1981) claim, in which he argued that PRO must not be governed and hence not case marked. In this scenario, and against Government and Binding (GB) schema in which some languages adopted the notion of government for case assignment, but subsequently, INFL has no logical role on governing overt or covert subject and that a governer in SA comes in SVO order after the governee which violates GB rules. Accordingly, and on basis of such findings, I propose pro case to be licensed through the same feature: INFL. The proposition is supported by Chomsky's (1982) contribution when he came across with the conclusion that pro and AGR relation is not essentially and directly assigning case to pro. Rather, as he and later Harbert (1995) suggested that pro-case is assigned by INFL of two heads match features. The pro in previous sentence is, thus, assigned case by INFL as not a governing category but as a feature of case license. Following Chomsky \& Lasnik (1993) proposal, I say that a pro as in (9) has case licensed by agree relation between pro and verbal features. The process involves checking match of [AGR, T] features on both heads. I assume, according to (9) of embedded clause, that pro-drop is truly null due to the maximal projection $I^{0}$ consistency that shows full feature of [AGR, T]:

$\begin{array}{llllll}9) . \text { arad-a } & \text { ?talib-u } & {[? \mathrm{nn}} & \text { yaktub-a } & \varnothing & \text { ?nnass-a }]\end{array}$

Wish.3.sg.msc.Pst the student. Nom that (he) write.3.sg.msc ec.3.sg.msc the text.Acc

"the student wanted to write pro the text"

Nominative case is license to pro comes after the operation of checking that requires verb movement (yaktub-a) to TP node to check its [T] feature. Obviously, the verb is in present tense, and has full inflection with regard to tense. Likewise, and for the purpose of checking AGR feature, the verb is said to raise more step to AGR node to check this feature with [Ø]. The $\phi$-features of the verb (yaktub-a) and [Ø] are compatible as seen in (9). Accordingly, and with regard to this property of the embedded clause, a pro is dropped at LF form to have structure of (9) at phonetic form (PF). The process is illustrated in diagram 1: 

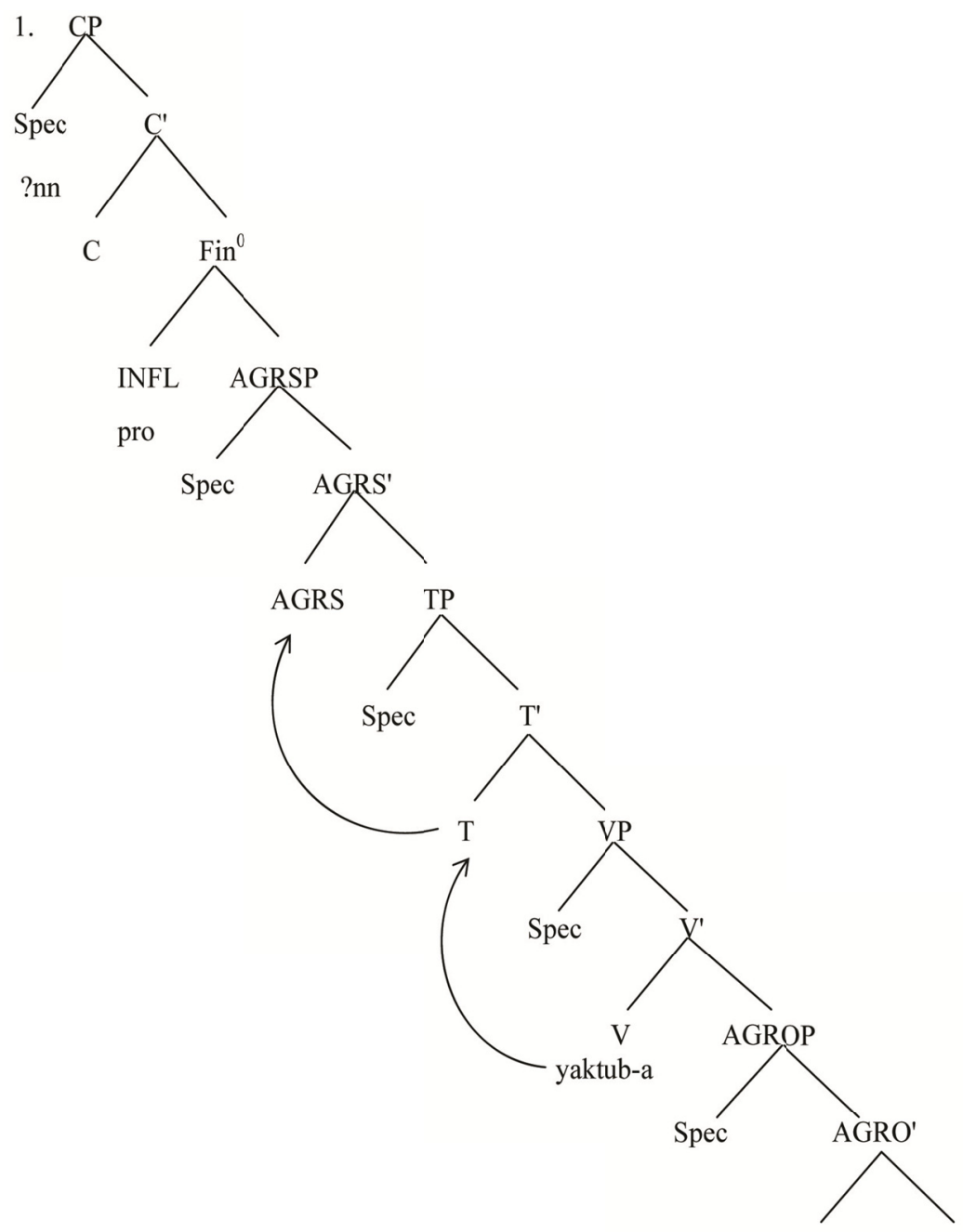

AGRO

?nnass-a

Diagram 1.

Sentence (9) shows match between pro $\phi$-features and the same set of the verb (yass'ad-a). The diagram, as seen, involves pro as a subject that moves from Spec-VP, as earlier proposed by Koopman \& Sportiche (1991), to Spec-IP for the purpose of case license by (AGR) head relation. This type of movement in earlier version of minimalism has been called by Chomsky (1995) as (Greed), but later replaced by the concept of (Enlightened Self Interest) that has been coined by Lasnik (1995). Accordingly, dropping of pro seems to be pertinent to the idea that once case feature is checked at the new position, this feature is no longer remains for A- movement. However, the pro, here, as empty category seems to have interpretable features that permit it to be checked against those of AGR head of the finite verb. In such state, one can say that rich verbal morphology contributes in identifying pro in SA. And in this way, pro that proceeds overt subject and verb can be said to be licensed for case by AGR(eement) process- see Chomsky (1999, p. 313)- as seen in (10):

\section{0). [IP pro I[VP ya -rkab-u ?ssayara-t -a]]}

This argumentation seems plausibly to draw inference that rich verbal morphology of SVO order of SA validates case license to pro as well as dropping through coindexing of pro with the verb. This proposition is supported cross linguistically by Borer (1986) and Rizzi (1986) who suggest that this is achieved-Pro identificationthrough co-indexation with rich AGR morphology from syntactic feature of categories surrounded it. The pro is having, then, interpretable feature, and it has estimated reference that can be estimated from non-linguistic context. In case of VSO order, the verb has different possibilities to NP subject. If the subject is lexical, then some forms pertains incomplete agreement as in (11. a), contrasted to (1. b) that shows full agreement. On the 
other side, when the structure has null subject, then it manifests complete agreement as in (12):
11). a. katab-a
?ttulab-u
?ddars-a
PARTIAL AGREEMENT

Write.pst.sg.msc.3 the students.3.plu. msc.NOM

the. lesson.ACC

"the students wrote the lesson"
b. katab-a
Ali-un
?ddars-a
write. pst.sg.msc.3
Ali. pst.sg.msc.3. NOM
the. Lesson. ACC
"Ali wrote the lesson"
12). Kataba-t
pro
?ddars-a
FULLAGREEMENT
Write.pst.3.sg.fem
pro. 3.sg.fem
the lesson
"She wrote the lesson"

FULLAGREEMENT

However, there is a logical account why the verb in VSO order behaves differently with regard to agreement between subject and verb. Back to case license which seems to centralize on the idea that $\left[\mathrm{T}^{0}\right]$ has two features: verbal and nominal that must be checked in the course of derivation at LF. In this matter, Chomsky $(1995,1999)$ has proposed that in V-features, the relation is an interaction of [T] with [V] feature(s), whereas D-feature stands for tense-to-subject interaction feature(s) that should be checked at verbal and nominal heads at LF. Arabic has strong verbal features of [INFL], but invariable in VSO. From this, one can claim that SA maintains strong D-features that requires pro to be checked for these features. In such case, pro has not to move out of Spec-VP at LF. But the minimalist concept of Extended Projection Principle (EPP) imposes pro to move into Spec-IP to be CHECKED for case. Thus, beside both EPP and Checking, strong feature of D-feature of INFL, it seems to motivate pro to move over to Spec-IP to be licensed nominative case after agreement checked via Spec-head configuration at AGRSP position.

The process of pro checking involves both case and agreement that must be checked in derivation course. Pro as a subject is said to be feature-checked at Spec-head agreement at [IP] as seen in (14.a). In this position, there should be match features at the functional head [INFL] and these equivalents of pro encoded in Spec-IP. This scenario helps in derivation convergence. Otherwise, it will crash. This position, is thus, involves agreement and case checking respectively. Further, it triggers verb to move for [T] feature checking as shown in diagram 2 for sentence (13).
13). Kataba-t
pro
?ddars-a
Write.pst.3.sg.fem pro. 3.sg.fem
"She wrote the lesson"
the. lesson

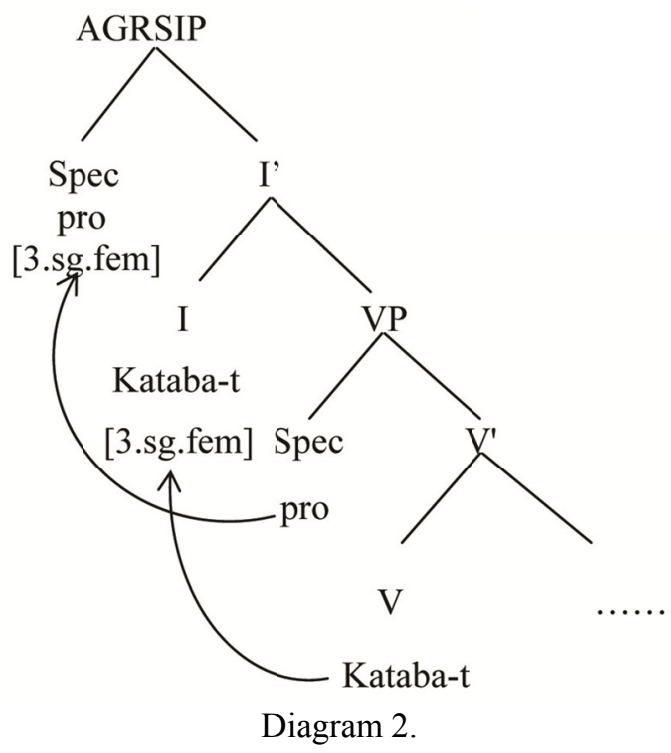


The strong features of the verb (Kataba) seems central to interpret such features in SA in the sense that it motivates verb to move up from VP- shell for feature checking position of I. The process seemingly might be strange to syntactic models of Government and Binding and Minimalist Program because move is always associated with NPs. In fact, this is possible in English also. For this state, Lasnik (2001) argued in his work on Pseudo gapping construction that an object movement to AGRO provides a lucid evidence that a verb goes in a short movement that locates it before the object. Therefore, we can admit that a verb raises to check its $\phi$-features and tense against those of INFL head. Once these features get checked, they will be deleted before PF.

In the previous finite clause, subject position can be occupied by null pro which has full interpretation of subject. This state of affairs can be said to underlie verbal agreement [INFL] results into pro drop in such clause. So, one can say that rich verbal agreement permits verb overt movement and case license as well. But the question arises here is that such state serves directly to pro drop in SA by identified morpho-syntactic properties of pro that can be recovered from the verb [INFL] domain? Cross-linguistically, other languages have been claimed to have this proposal. For this, Holmberg (2005) argued that $\phi$-features in [T] and [Agr] are interpretable in Null-Subject Languages, and pro is therefore redundant.

\section{Checking Features and Pro}

As said earlier, checking verbal as well as pronominal features is necessary for derivation convergence. Given this, one can say that pronominal $\phi$-features are expected to match those of INFL head, and then subject features of agreement and case will be valued. The process of checking features is, thus, takes place between the head and its specifier through Spec-head configuration. If the features of the subject that are encoded in IP are checked, then features such as agreement, case and tense can be also valued. One fact here is that verb in SA has strong features, which allows it to move overtly or covertly from VP bar into IP to check its bundle features against those INFL head as proposed by Radford $(1997,2004)$. If these features match those of the functional head (INFL), then the verbal features will be valued and hence licensed. Once these features are valued and interpreted, they will be deleted before PF. The refinement now, is that, the relationship between features license and pro null subject. One proposal is that a complete features checking and interpretation can be suggested to results into pro-drop which, in fact, can be recovered or recompensed in the rich verbal affixation.

\section{EPP and Pro-drop}

Extended Projection Principle (EPP) has been proposed for the purpose well-formedness condition which imposes each clause to have a subject. Even if there is no overt subject that occupies the Spec-IP position, there must be a subject projected even as empty or expletive. EPP is said to induce subject move from VP-position into Spec-IP/TP to satisfy this position. However, with reference to the works carried out by Barbosa (1995, 2000), Pollock (1997) and Kato (1999) who stressed that no EPP driven by XP- movement to IP/TP in NSLs, one can suggest that in the light of syntactic theory evolution, concepts are probably to change on the basis of lucid evidences. Thus, pre-verbal (overt or null) subject might be claimed to show no A- movement, rather it remains in situ. The NP-subject position of finite or non-finite verb is not inevitably realized phonetically which can be enforced by the fact that the same verb can assign external theta role to the variable subject form in both cases: overt and null at Spec-IP. This, further, can be attributed to the strong feature that a verb such as in SA exhibits as Chomsky (1995, p. 199) pointed to that. This state is attributed also to rich INFL/AGR morphology of Spec-IP. However, instead of A-movement, the operation could be replaced by Chomsky's (2000, 2001, 2005) concept of AGREE relation which is based on feature-movement for checking as depicted at LF. In such case, a pro may not undergo a move from VP into Spec-IP in (11) or does not do so in (14) to be moved from VP-shell into Spec-VP. This proposition, involves two issues: the first is that a pro may not move if it has full-AGREE inflection, and the second is that its features might move for this purpose.

\section{Conclusion}

The presence of null pro in SA structures is partial. In some structures it is a pro-drop and in some it is NSL. Being pro-drop language is a syntactic property seems compatible with economy principle of minimalism. Given this principle, we can claim that the absence of pronominal subject in such constructions is more economic than its presence which requires overt phonetic representation at PF. From this study, we can say that SA is partial pro-drop language. Thus pro-drop is cross-language varied in which some non-finite forms show poor inflection, but maintain null subject. The study displays that the motive for pro-drop is features license after being checked and interpreted. The pro is, in fact, has a tangible trace after being dropped; it can be recovered from features of INFL of the verb. The universal principle is that SA is pro-drop language due to rich INFL. Despite this SA principle, the deviance is that forms such as imperative (and equational sentence) with poor INFL have dropped subject which decreases $[\mathrm{AGR}]$ feature match at Spec-IP on the expanse of [T]. One way to account for this is 
through topic chain being inferred from context or proceeding structure. Another inference can be found that agree relation between goal and probe features (requires match) results to case assignment which consequently hints to pro-drop. This relation is seen as alternative to A-movement in which features move to be checked and interpreted at LF.

\section{References}

Barbosa, P. (1995). Null Subjects. Ph.D. Dissertation. Cambridge, Mass: MIT.

Barbosa, P. (2000). Clitics: A Window into the Null Subject Property. In J. Costa (Ed.), Portuguese Syntax: Comparative Studies (pp. 31-93). New York: Oxford Press.

Borer, H. (1986). I-subjects. Linguistic Inquiry, 17, 375-416. Retrieved from http://www.jstor.org/stable/4178498

Chomsky, N. (1981). Lectures on Government and Binding: The Pisa Lectures (7th ed.). Holland: Foris Publications. Reprint. Berlin and New York: Mouton de Gruyter, 1993. http://dx.doi.org/10.1515/9783110884166

Chomsky, N. (1995). The Minimalist Program. Cambridge, Mass: MIT Press. http://dx.doi.org/10.7551/mitpress/9780262527347.001.0001

Chomsky, N. (1999). Derivation by phase. Cambridge, MA: MIT.

Chomsky, N. (2000). Minimalist Inquiries: The Framework. In R. Martin, D. Michaels \& J. Uriagereka (Eds.), Step by Step: Essays on Minimalist Syntax in Honor of Howard Lasnik (pp. 89-156.). Cambridge, Mass.: MIT Press.

Chomsky, N. (2001). Derivation by Phase. In M. Kenstowicz (Ed.), Ken Hale: A Life in Language (pp. 1-52). Cambridge, Mass.: MIT Press.

Chomsky, N. (2005). On Phases. Cambridge, Mass.: http://dx.doi.org/10.7551/mitpress/9780262062787.003.0007

Chomsky, N., \& Lasnik, H. (1993). The Theory of Principles and Parameters. In J. Jacobs, A. Von Stechow, W. Sternefeld, \& T. Vennemann (Eds.), Syntax: An International Handbook of Contemporary Research (pp. 506-569). Berlin: Mouton de Gruyter. http://dx.doi.org/10.7551/mitpress/9780262527347.003.0001

Holmberg, A. (2005). Is There a Little Pro? Evidence from Finnish. Linguistic Inquiry, 36, 533-564. http://dx.doi.org/10.1162/0024389057744664322

Jaeggli, O., \& Safir, K. (1989). The Null Subject Parameter and Parametric Theory. In O. Jaeggli \& K. Safir (Eds.), The Null Subject Parameter. Kluwer, Dordrecht. http://dx.doi.org/10.1007/978-94-009-2540-3_1.

Jespersen, O. (1924). The philosophy of grammar. London: Allen and Unwin. http://dx.doi.org/10.2307/2914398

Kato, M. (1999). Strong Pronouns, Weak Pronominals and the Null Subject Parameter. Probus, 11, 1-37. In M. Kato \& E. Negrão (Eds.), The Null Subject Parameter in Brazilian Portuguese. Frankfurt: Vervuert-Ibero Americana. http://dx.doi.org/10.1515/prbs.1999.11.1.1.

Koopman, H., \& Sportiche, D. (1991). The position of subjects. Lingua, 85(1), 211-258. http://dx.doi.org/10.1016/0024-3841(91)90022-w.

Labov, W. (1994). Principles of Linguistic Change: Internal Factors. Oxford: Blackwell. http://dx.doi.org/10.1075/s1.21.1.17clo

Lasnik, H. (1995). Case and Expletives Revisited: On Greed and Other Human Failings. Linguistic Inquiry, 26(4), 615-633. Retrieved from http://www.jstor.org/stable/4178916.

Lasnik, H. (2001). A Note on the EPP. Linguistic Inquiry, 32, 256-362. http://dx.doi.org/10.1162/ling.2001.32.2.356.

McCarthy, J. (1981). A Prosodic Theory of Nonconcatenative Morphology. Linguistic Inquiry, 12(3), 373-418. Cambridge, Mass.: MIT. http://www.jstor.org/stable/4178229

Ouhalla, J. (1999). Introducing Transformational Grammar: From Principles and Parameters to Minimalism (1st and 2nd ed.). Oxford, Oxford University Press.

Pollock, J. Y. (1997). Langage et Cognition: Introduction au Programme Minimaliste de la Grammaire Générative. Paris: Presses Universitaires de France. http://dx.doi.org/10.2307/3736279

Radford, A. (1997). Syntax: A Minimalist Introduction. Cambridge: Cambridge University Press. https://doi.org/10.1017/CBO9781139166898. 
Radford, A. (2004). Minimalist Syntax: Exploring the Structure of English. Cambridge: Cambridge University Press. https://doi.org/10.1017/CBO9780511811319.

Rizzi, L. (1982). Issues in Italian syntax. Dordrecht: Foris. http://dx.doi.org/10.1515/9783110883718

Rizzi, L. (1986). Null objects in Italian and the theory of pro. Linguistic Inquiry, 17, 501-557.

Taraldsen, K. T. (1978). On the NIC, vacuous application and the that-trace filter. Mimeographed, MIT, Indiana Linguistics Club, 1980.

Wright, W. (1967). A Grammar of the Arabic Language. Cambridge: Cambridge University Press.

\section{Note}

Note 1. Jespersen 1924 remarked that languages such as Latin, Finish and Hebrew have distinction in $\phi$-features in verbs. This cross-linguistic property provides an opportunity to subject implicit form within the structure. This statement supports the idea that verbal rich INFL that results to implicit subject.

\section{Copyrights}

Copyright for this article is retained by the author(s), with first publication rights granted to the journal.

This is an open-access article distributed under the terms and conditions of the Creative Commons Attribution license (http://creativecommons.org/licenses/by/4.0/). 